\title{
VERZEICHNIS DER SCHRIFTEN VON JÓZEF DARSKI
}

\section{Verfasserschriften, Monographien}

1973. Morphonologie der Reste der ehemaligen niederdeutschen Kolonialmundart von Sepolno Krajeńskie. Poznań: Adam-Mickiewicz-Universität (unveröffentlichte Dissertation).

1987. Linguistisches Analysemodell. Definitionen grundlegender grammatischer Begriffe. Poznań: Wydawnictwo Naukowe UAM.

1999. Bildung der Verbformen im Standarddeutschen. Tübingen: Stauffenburg.

2004. Linguistisches Analysemodell. Definitionen grundlegender grammatischer Begriffe. 2., völlig neu bearbeitete und ergänzte Auflage. Poznań: Wydawnictwo Naukowe UAM.

2010. Deutsche Grammatik: ein völlig neuer Ansatz. Frankfurt a. M. u. a.: Peter Lang Verlag.

2012. Gramatyka niemiecka z uwagami konfrontatywnymi. Poznań: Wydawnictwo Naukowe UAM.

2015. Deutsche Grammatik: ein völlig neuer Ansatz. Neubearbeitung für Deutsch-als-Fremdsprache-Unterricht. 2., erweiterte Auflage. Frankfurt a. M. u. a.: Peter Lang Verlag.

\section{Editorische Schriften}

1993. Darski, Józef/Vetulani, Zygmunt (Hgg.): Sprache - Kommunikation - Informatik. Akten des 26. Linguistischen Kolloquiums, Poznań 1991. Tübingen: Max Niemeyer Verlag.

\section{Artikel, Studien, Kommuniques}

1967. „Nowe spojrzenie germanistów radzieckich na deklinację rzeczowników w języku niemieckim.“ Języki obce w szkole 11, 5, 300-303. 
1973. „Diachronische Betrachtung des Lautbestandes der ehemaligen niederdeutschen Mundart von Sępolno Krajeńskie.“ Lingua Posnaniensis 17, 81-96.

1978. „Die Einteilung der Verben nach der Art der Flexion und zur Bildung der Verbformen im Deutschen. Linguistische Studien, Reihe A, Arbeitsberichte 49, 65-93.

1979. „Didaktische Grammatik für Ausländer?“ Studia Germanica Posnaniensia 7, 173-187.

1979. „Unveröffentlichte Diplomarbeiten im Bereich der kontrastiven Linguistik im Institut für Germanische Philologie der Adam-Mickiewicz-Universität zu Poznań." Studia Germanica Posnaniensia 7, 211-218.

1979. „Die Adjektivdeklination im Deutschen.“ Sprachwissenschaft 4, 2, 190-205.

1980. „Morphonologie der ehemaligen niederdeutschen Kolonialmundart von Sępolno Krajeńskie." Germanistische Dissertationen in Kurzfassung, Bern, 96-100.

1980. „Wie kann man erfolgreich eine Fremdsprache erlernen.“ Glottodidactica 13, $105-115$.

1980. „Die Deklinationstypen der Substantive im Deutschen.“ Studia Germanica Posnaniensia 9, 55-70.

1982. „Próba obiektywnego oceniania ucznia z języka obcego.“ Neodidagmata 15 , $183-187$.

1983. „O nowym sposobie klasyfikacji wyrazów na części mowy.“ Poznańskie Towarzystwo Przyjaciót Nauk, Sprawozdanie nr 97-99 za 1979-81. Poznań: Wydział Filologiczno-Filozoficzny. 181-185.

1984. „Rola Lektora w procesie nauczania języka.“ Przeglad Glottodydaktyczny 6, 93-106.

1984. „Zur Definition der Präposition im Deutschen.“ Studia Germanica Posnaniensia $13,27-30$.

1984. „Die pädagogische Aufbereitung der Adjektivdeklination im Deutschen.“ Studia Germanica Posnaniensia 13, 31-44.

1984. „Definicja fonemu.“ Poznańskie Towarzystwo Przyjaciót Nauk, Sprawozdania nr 100 za 1982. Poznań: Wydział Filologiczno-Filozoficzny. 181-185.

1985. „Die Einteilung der Substantive in Deklinationsklassen nach ihren syntaktischen Exponenten im gegenwärtigen Deutsch.“ In: Lipczuk, Ryszard (Hg.): Göppinger Arbeiten zur Germanistik Nr. 447 (= Grammatische Studien. Beiträge zur germanistischen Linguistik in Polen). Göppingen: Kümmerle. 83-127.

1988. „Deutsche Grammatik für Ausländer?“ Glottodidactica 19, 137-148.

1989. „Die Wortgrenzen im Deutschen.“ In: Reiter, Norbert (Hg.): Sprechen und Hören. Akten des 23. Linguistischen Kolloquiums, Berlin 1988. Tübingen: Niemeyer. 255-264.

1989. „Die präskriptive Norm und die Entwicklungstendenzen in der Deklination des Substantivs im gegenwärtigen Deutsch.“ Studia Germanica Posnaniensia 16, $65-79$. 
1990. „O większą efektywność nauczania gramatyki opisowej języka niemieckiego.“ Materiały i Sprawozdania Wyższej Szkoły Pedagogicznej w Krakowie 21, 29-36.

1990. „Przygotowanie uczniów do samokształcenia w zakresie języków obcych.“ Neofilolog, Biuletyn Polskiego Towarzystwa Neofilologicznego 2, 31-38.

1991. „Die Verweiswörter im Deutschen.“ In: Klein, Eberhard/Pouradier Duteil, Françoise/Wagner, Karl Heinz (Hgg.): Betriebslinguistik und Linguistikbetrieb. Akten des 24. Linguistischen Kolloquiums, Universität Bremen, 4.-6. September 1989. Tübingen: Niemeyer. 201-206.

1991. „Rola gramatyki w nauczaniu języków obcych.“ Biuletyn Polskiego Towarzystwa Neofilologicznego 3, 11-20.

1991. „Ist eine übereinzelsprachliche Definition des ,Finitums“ möglich?“ In: Feldbusch, Elisabeth/Pogarell, Reiner/Weiß, Cornelia (Hgg.): Neue Fragen der Linguistik. Akten des 25. Linguistischen Kolloquiums, Paderborn 1990. Tübingen: Niemeyer. 407-413.

1993. „Gibt es eine klare, widerspruchsfreie deutsche Grammatik?“ In: Darski, Józef/ Vetulani, Zygmunt (Hgg.): Sprache - Kommunikation - Informatik. Akten des 26. Linguistischen Kolloquiums, Poznań 1991. Tübingen: Niemeyer. 325-331.

1993. „Jak uczyć fonetyki?““ In: Maleńczyk, Halina (Hg.): Polska w zjednoczonej Europie. Nauczanie języków obcych. Lublin: Uniwersytet Marii Curie-Skłodowskiej. 27-33.

1994. „Zur Bildung des Passivs im Deutschen.“ In: Haiwachs, Dieter W./Stütz, Irmgard (Hgg.): Sprache - Sprechen - Handeln. Akten des 28. Linguistischen Kolloquiums, Graz 1993. Tübingen: Niemeyer. 45-51.

1994. „Welche und wieviel Grammatik braucht der Sprachschüler?“, Glottodidactica $22,153-164$.

1995. „Der Begriff der Valenz und sein Beitrag zur exakteren Definition mancher Wortarten.“ In: Eichinger, Ludwig M./Eroms, Hans-Werner (Hgg.): Dependenz und Valenz. Hamburg: Buske. 233-242.

1995. „Welche Grammatik braucht der Lerner?“ In: Dittmar, Norbert/Rost-Roth, Martina (Hgg.): Deutsch als Zweit- und Fremdsprache. Frankfurt a. M. u. a.: Peter Lang Verlag. 95-105.

1995. „Die deutsche Substantivdeklination im Fremdsprachenunterricht.“ Neofilolog 9, 18-24.

1996. „Die Fugenelemente im Deutschen.“ In: Sroka, Kazimierz A. (Hg.): Kognitive Aspekte der Sprache. Akten des 30. Linguistischen Kolloquiums, Gdańsk 1995. Tübingen: Niemeyer. 50-54.

1996. „Die Wortarten des Deutschen. Ein neuer Ansatz.“ In: Wiktorowicz, Józef (Hg.): Studien zur deutschen und niederländischen Sprache und Kultur. Festschrift für Jan Czochralski. Warszawa: Instytut Germanistyki Uniwersytetu Warszawskiego. $39-59$. 
1996. „Die deutsche Substantivdeklination in pädagogischer Aufbereitung.“ Glottodidactica 24, 5-25.

1997. „Unterrichtsorientierte Einteilungen der Verben nach der Art der Flexion seit Adelung.“ In: Dębski, Antoni (Hg.): Plus ratio quam vis. Kraków: Wydawnictwo Uniwersytetu Jagiellońskiego. 67-76.

1998. „Stamm bzw. Wurzel und Endungen?“ In: Puppel, Stanisław (Hg.): Scripta manent. Poznań: Motivex. 85-97.

1999. „Kriterien und Verfahren zur Bestimmung der Wortklassen am Beispiel des Deutschen. Ein neuer Ansatz.“ In: Bańczerowski, Jerzy/Zgółka, Tadeusz (Hgg.): Linguam amicabilem facere. Ludovico Zabrocki in memoriam. Poznań: Wydawnictwo Naukowe UAM. 261-289.

1999. „Was ist Stamm?“ In: Beedham, Christopher (Hg.): Language and Parole in Synchronic and Diachronie Perspective. Selected Proceedings of the XXXIst Annual Meeting of the Societas Linguistica Europea, St Andrews 1998. Amsterdam u. a.: Pergamon. (An imprint of Elsevier Science). 149-165.

2000. „Czy końcówki adekwatnie odzwierciedlają stosunki syntaktyczne wyrazów tekstowych w zdaniu?“ In: Kielar, Barbara Z. u. a. (Hgg.): Problemy komunikacji międzykulturowej: lingwistyka, translatoryka, glottodydaktyka. Warszawa: Graf-Punkt. 19-34.

2000. „Die Personalendungen des Verbs im Deutschen.“ In: Kurpanik-Malinowska, Gizel/Ławnikowska-Koper, Joanna/Podobiński, Stanisław (Hgg.): Germanistische Texte II. Prace Naukowe Wyższej Szkoty Pedagogicznej w Częstochowie. Częstochowa: Wydawnictwo WSP. 141-157.

2001. „Deutsche Grammatik im 21. Jahrhundert.“ In: Grucza, Franciszek (Hg.): Tausend Jahre polnisch-deutsche Beziehungen. Sprache - Literatur - Kultur - Politik. Materialien des Millennium Kongresses 5.-8. April 2000, Warszawa. Warszawa: Graf-Punkt. 421-432.

2001. „Deutsche Grammatik. Ein neuer Ansatz.“ In: Grimm, Christa/Nagelschmidt, Ilse/Stockinger, Ludwig (Hgg.): Mannigfaltigkeit der Richtungen. Analyse und Vermittlung kultureller Identität im Blickfeld germanistischer Literaturwissenschaft. Leipzig: Leipziger Universitätsverlag. 97-105.

2002. „Hilfsverben? Auxiliarverben?“ In: Rapp, Reinhard (Hg.): Sprachwissenschaft auf dem Weg in das dritte Jahrtausend: Akten des 34. Linguistischen Kolloquiums in Germersheim 1999. Teil 1: Text, Bedeutung, Kommunikation. Frankfurt a. M. u. a.: Peter Lang Verlag. 309-316.

2003. „Vielfalt von Sprachen - Vielfalt von Theorien.“ In: Grucza, Franciszek (Hg.): Deutsch-polnische und gesamteuropäische Integration in Forschung, Lehre und Öffentlichkeitsarbeit der (polnischen) Germanistik. Materialien der Jahrestagung des Verbandes Polnischer Germanisten 02.-04. Mai 2003, Szczecin. Warszawa: Euroedukacja. 283-293. 
2004. „Die deutsche Grammatik in Theorie und Didaktik.“ In: Dębski, Antoni/Lipiński, Krzysztof (Hgg.): Perspektiven der polnischen Germanistik in Sprachund Literaturwissenschaft. Festschrift für Olga Dobijanka-Witczakowa zum 80. Geburtstag. Kraków: Wydawnictwo Uniwersytetu Jagiellońskiego. 299-311.

2004. „Sind sprachliche Einheiten fiktiv oder real?“ In: Grucza, Franciszek/ Schwenk, Hans-Jörg/Olpińska, Magdalena (Hgg.): Konstrukte und Realität in der Sprach-, Literatur- und Kulturwissenschaft sowie in der Geschichtsforschung und Sozialwissenschaft. Materialien der Jahrestagung des Verbandes Polnischer Germanisten 23.-25. April 2004, Poznań. Warszawa: Euroedukacja. 51-62.

2006. „Wortform, Lexem, semantisches Wort.“ In: Kotin, Michail L./Krycki Piotr/ Laskowski, Mark/Zuchewicz, Tadeusz (Hgg.): Das Deutsche als Forschungsobjekt und als Studienfach. Synchronie - Diachronie - Sprachkontrast. Akten der Internationalen Fachtagung anlässlich des 30jährigen Bestehens der Germanistik in Zielona Góra/Grünberg. Frankfurt a. M. u. a.: Peter Lang Verlag. $35-47$.

2006. „Textanalyse aufgrund allgemein menschlicher Sprachprinzipien.“ In: Simmler, Franz/Tomiczek, Eugeniusz (Hgg.): Wroctaw - Berlin. Germanistischer Brückenschlag im deutsch-polnischen Dialog. II. Kongress der Breslauer Germanistik. Band 1. Sprachwissenschaft. Wrocław/Dresden: Neisse Verlag. 215-223.

2006. „Agglutination auch im Deutschen?““ In: Kürschner, Wilfried/Rapp, Reinhard (Hgg.): Linguistik International. Festschrift für Heinrich Weber. Lengerich-Berlin u. a.: Pabst Science Publishers. 529-541.

2007. „Die Kasuskennzeichnung im Standarddeutschen.“ In: Grzywka, Katarzyna u. a. (Hgg.): Kultura - Literatura - Język. Prace ofiarowane Profesorowi Lechowi Kolago w 65. rocznicę urodzin. Warszawa: Instytut Germanistyki Uniwersytetu Warszawskiego. 868-879.

2008. „Die Rolle der natürlichen und linguistischen Grammatik bei der Beherrschung einer Fremdsprache.“ Studia Germanica et Romanica 1/2008, 95-129.

2009. „Das Genus Verbi im Deutschen.“ Kwartalnik Neofilologiczny 1/2009, 3-23.

2010. „Jak można perfekcyjnie opanować język obcy?“ In: Pawlak, Mirosław/Waniek-Klimczak, Ewa (Hgg.): Mówienie w języku obcym - sukcesy i porażki uczenia się i nauczania. Kalisz: Wydział Pedagogiczno-Artystyczny UAM. $37-49$.

2011. „Allgemein menschliche Sprachprinzipien als Grundlage eines neuen linguistischen Analysemodells.“ In: Kotin, Michail L./Kotorova, Elizaveta G. (Hgg.): Geschichte und Typologie der Sprachsysteme. Heidelberg: Winter. 29-49.

2012. „Ausnahmen in Grammatiken.“ In: Grzywka, Katarzyna (Hg.): Kultura, literatura, język: pogranicza komparatystyka. Prace ofiarowane Profesorowi Lechowi Kolago w 70. rocznice urodzin. T. 2. Warszawa: Instytut Germanistyki Uniwersytetu Warszawskiego. 1419-1428. 


\section{Rezensionen}

1994. Wolfgang Rüg, Andreas Tomaszewski (1993): „Grammatik mit Sinn und Verstand. 20 Kapitel deutsche Grammatik für Fortgeschrittene. München: Verlag Klett Edition Deutsch GmbH,“ Glottodidactica 22, 213-215.

1998. Gisela Zifonun u. a. (1997): „Grammatik der deutschen Sprache. Band 1-3. 2569

S. Berlin/New York.“ Convivium. Germanistisches Jahrbuch Polen, 459-463. 